\title{
Molecular markers of anti-malarial drug resistance in Lahj Governorate, Yemen: baseline data and implications
}

\author{
Reem A Mubjer ${ }^{1 *}$, Ahmed A Adeel ${ }^{2}$, Michael L Chance ${ }^{3}$ and Amir A Hassan ${ }^{3}$
}

\begin{abstract}
Background: This is an investigation of anti-malarial molecular markers coupled with a therapeutic efficacy test of chloroquine (CQ) against falciparum malaria in an area of unstable malaria in Lahj Governorate, Yemen. The study was aimed at assessment of therapeutic response to CQ and elucidation of baseline information on molecular markers for Plasmodium falciparum resistance against CQ and sulphadoxine/pyrimethamine (SP).

Methods: Between 2002 and 2003 the field test was conducted according to the standard WHO protocol to evaluate the therapeutic efficacy of CQ in 124 patients with falciparum malaria in an endemic area in Lahj Governorate in Yemen. Blood samples collected during this study were analysed for $P$. falciparum chloroquine resistance transporter gene (pfcrt)-76 polymorphisms, mutation pfcrt-S163R and the antifolate resistance-associated mutations dihydrofolate reductase (dhfr)-C59R and dihydropteroate synthase (dhps)-K540E. Direct DNA sequencing of the pfcrt gene from three representative field samples was carried out after DNA amplification of the 13 exons of the pfcrt gene.
\end{abstract}

Results: Treatment failure was detected in $61 \%$ of the 122 cases that completed the 14-day follow-up. The prevalence of mutant pfcrt T76 was 98\% in 112 amplified pre-treatment samples. The presence of pfcrt T76 was poorly predictive of in vivo CQ resistance (PPV $=61.8 \%, 95 \% \mathrm{Cl}=52.7-70.9$ ). The prevalence of $d$ fr $\mathrm{Arg}-59$ mutation in 99 amplified samples was 5\%, while the dhps Glu-540 was not detected in any of 119 amplified samples. Sequencing the pfcrt gene confirmed that Yemeni CQ resistant $P$. falciparum carry the old world (Asian and African) CQ resistant haplotype CVIETSESI at positions 72,73,74,75,76,220,271, 326 and 371 .

Conclusion: This is the first study to report baseline information on the characteristics and implications of antimalarial drug resistance markers in Yemen. It is also the first report of the haplotype associated with CQR P. falciparum parasites from Yemen. Mutant pfcrtT76 is highly prevalent but it is a poor predictor of treatment failure in the study population. The prevalence of mutation dhfrArg59 is suggestive of emerging resistance to SP, which is currently a component of the recommended combination treatment of falciparum malaria in Yemen. More studies on these markers are recommended for surveillance of resistance in the study area.

\section{Background}

In Yemen the population at risk of malaria constitutes $81 \%$ of the total population, with an estimated one million cases in 2009 [1]. Most of the studies on antimalarial drug efficacy that were carried out in the 1980s and the early 1990s were done in the southern parts of the country. These were mainly in vivo studies based on

\footnotetext{
* Correspondence: reemmubjer@yahoo.co.uk

'Genetics and Immunology, Department of Physiological Sciences, Faculty of Medicine and Health Sciences, Aden University, Yemen

Full list of author information is available at the end of the article
}

the standard WHO 7-day test to assess response of Plasmodium falciparum to chloroquine (CQ ) [2]. These studies reported no significant levels of CQ resistance during this period [3,4]. Starting from 2002, the revised WHO protocols were introduced for monitoring the therapeutic efficacy of anti-malarial drugs to $P$. falciparum in Yemen [5]. The present report gives an account of a therapeutic efficacy test on CQ conducted in 2002-2003 in Al-Musiemeer Hospital in Lahj Governorate and an investigation of molecular markers for $\mathrm{CQ}$ and sulphadoxine/pyrimethamine (SP) resistance in

\section{Biomed Central}

(c) 2011 Mubjer et al; licensee BioMed Central Ltd. This is an Open Access article distributed under the terms of the Creative Commons Attribution License (http://creativecommons.org/licenses/by/2.0), which permits unrestricted use, distribution, and reproduction in any medium, provided the original work is properly cited. 
the same study samples. The findings establish baseline data on molecular markers of anti-malarial drug resistance, which could help in the surveillance of drug resistance in this area and in Yemen.

CQ resistance is associated with a point mutation at codon 76 of the $P$. falciparum chloroquine resistance transporter $(p f c r t)$ gene, which is highly correlated with increased clinical CQ tolerance and treatment failure [6] [7][8]. Other point mutations in P. falciparum multidrug resistance gene 1 ( $p f m d r 1$ ) mainly N86Y, Y183F, S1034C, N1042D, and D1246Y, have also been shown to modulate CQ resistance [9]. In some areas, where CQ resistance was highly prevalent, studies have highlighted that withdrawal of CQ drug pressure may lead to a reversion to CQ-susceptible phenotypes as indicated by molecular marker studies [10]. Such a phenomenon might be missed if molecular prevalence surveys have not been conducted. Moreover, increasing evidence currently points to a possible role for both pfcrt and $p f m d r-1$ in resistance to other anti-malarial drugs [11,12]. A recent global meta-analysis concluded that both pfcrt and pfmdr1 polymorphisms are associated with chloroquine resistance, with the odds ratio (OR) of the pfcrt K76T mutation for therapeutic failure after chloroquine exceeding 7.0 at 28 days and 2.0 at day 14 [13].

Resistance of falciparum malaria parasites to antifolates is associated with mutation in dihydrofolate reductase $(d h f r)$ and dihydropteroate synthase (dhps), which are enzymes involved in the parasite's folate synthesis [14-18]. Although (SP) alone is no longer recommended as a treatment regimen for falciparum malaria, it is still widely used in Yemen in combination with artesunate (AS) as first-line treatment of uncomplicated falciparum malaria. It remains essential that efficacy of the SP component should be closely monitored to ensure the effectiveness of the combination therapies that include it. Estimation of the prevalence of the molecular markers of $\mathrm{SP}$ and CQ resistance and validation of the association of mutations with resistance in different settings is needed for local policy guidance and for contributing to a global map for anti-malarial drug resistance [19].

\section{Methods}

\section{Field therapeutic efficacy test}

A therapeutic efficacy test was conducted according to the WHO protocol to evaluate CQ against falciparum malaria [5] between October 2002 and January 2003 in a rural hospital in Al-Musiemeer district, Lahj governorate in the south-east of Yemen. All febrile patients coming to the health centre during the study period were screened for parasitaemia and were subjected to a pre-treatment examination. Subjects were included if they were above six months of age, had a measured axillary temperature $\geq$ $37.5^{\circ} \mathrm{C}$ or a history of fever during the last 24 hours, had a positive $P$. falciparum mono infection and a parasite density of 1,000-200,000 parasites/ $\mu$ l of blood, if they were able to take oral medication with no history of intolerance to chloroquine, able to come for follow-up visits and have easy access to the health facility. An informed consent was obtained from all patients or guardians for children. Patients were excluded from the study if they had any sign of danger, severe malaria, severe malnutrition, concomitant other febrile illness that can interfere with the clear classification of the outcome, or if the patient was pregnant. A history of previous anti-malarial drug use was not an exclusion criterion; however, the information on previous use was carefully collected and recorded for each patient. Consecutive patients presenting to the health centre during the implementation of the study with symptoms suggestive of malaria and positive thick smear blood screening were enrolled in the study if they satisfied all the inclusion criteria. A hundred and twenty four cases were enrolled to the study. The sample size was calculated using Statcalc (Epi info Version 6). Since the treatment failure rate was unknown, and according the WHO guidelines, the expected prevalence of treatment failure (P) was assumed to be $50 \% .10 \%$ precision level and 95\% confidence level were used in calculation. The sample size required was 96 patients. An expected follow-up loss of $10 \%$ was added to minimize the possible bias due to it.

Data were entered in a special questionnaire that included all necessary study variables. To guide the treatment doses, patients were weighed on a reliably calibrated scale. Axillary temperature was recorded with a reliable, tested electronic thermometer. For microscopic blood examination, two blood slides were always taken for each patient, a thick film (for rapid staining and screening for parasitaemia while the patient is in attendance), and a thick and a thin film on the same slide for subsequent standard staining to calculate parasite density. Finger-prick blood was collected before treatment and during follow-up from each patient on FTA ${ }^{\circledR}$ Classic Cards (Whatman ${ }^{\circledR}$ BioSience) or ordinary Whatman No. 3 filter papers. The name of the patients, their numbers, day and date of collection were written on each filter paper. Each filter paper with blood was stored in individual plastic bag with silica gel and kept for subsequent molecular analysis. Slides of all patients were re-examined separately by two microscopists in the central laboratory of the Roll Back Malaria Programme.

WHO provided chloroquine (IDA-HOLLAND, Batch No.1636, expiry date October 2005), was administered in a total dose, $25 \mathrm{mg} / \mathrm{kg}$ body weight, under direct supervision, as a three-day course as follows: $10 \mathrm{mg} / \mathrm{kg}$ in Day 0, $10 \mathrm{mg} / \mathrm{kg}$ in Day 1 and $5 \mathrm{mg} / \mathrm{kg}$ in Day 2. During the three days, patients, especially children, were observed for one hour after administration of the drug. If they 
vomited the drug within 30 minutes of its administration, the drug was re-administered with the same dose, if vomited again the patient was excluded from the study. Patients were followed on an outpatient basis on Day 0, Day 1, Day 2, Day 3, Day 7, Day 14 and on any other day between the scheduled days in case of any health concern. The clinical condition, body temperature, parasitaemia were assessed at each visit. Blood samples were collected on filter papers on day 0 , day 3 , day 7 , and on day 14 or the day of classification. The clinical and parasitological responses were classified according to the criteria of the standard WHO protocol into early treatment failure (ETF), late parasitological failure (LPF), late clinical failure (LCF) and adequate clinical and parasitological response (ACPR). Patients who were classified as a treatment failure were given the recommended dose of the second line treatment (SP). Two children developed signs of severe malaria (convulsions) during the follow-up period were given the first dose of parenteral quinine and taken urgently to the appropriate health facility.

\section{Molecular marker analysis}

The molecular work started with testing three different methods for the extraction of DNA; namely the methanol fixation-heat extraction method, the FTA purification reagent and the QIAGEN kit extraction method from ordinary Whatman No. 3 filter papers and Whatman FTA $^{\circledR}$ Card. The three methods of extraction gave the same results when extracted DNA (from both ordinary Whatman No. 3 filter papers and FTA ${ }^{\circledR}$ Cards) was used to amplify the pfcrt gene. It was decided to use the Methanol-Fixation Heat Extraction method because it was simple, effective, economic and feasible in poor resource countries like Yemen.

DNA was extracted from dried blood spots on filter paper using methanol-fixation/ heat extraction method as described by Plowe et al [17]. The PCR method developed by Djimde et al [20] was used to detect the pfcrtK76T mutation. It involves a nested PCR to amplify the region surrounding position 76 followed by restriction enzyme digestion to detect the presence of the mutant allele (Thr).

To detect the mutation S163R at pfcrt the protocol developed by Johnson [21], which is based on a nested PCR followed by restriction enzyme digestion was performed. DNA from the laboratory isolate K1AM that harbours the S163R mutation and DNA from 3D7 strain that lacks this mutation were used as controls, water was used as a negative control. To increase the sensitivity of the detection of the $d h f r-59$ polymorphism, two different PCR and restriction enzyme digestion protocols were used, one developed by Plowe et al [17] using Bsr GI enzyme for restriction digestion. The other method was that developed by Duraisingh et al [22] and uses XmnI enzyme for restriction digestion.

A nested PCR reaction followed by restriction enzyme digestion was used to detect dhps polymorphism at codon 540. The method used was developed by Plowe et al [17]. The distinction between recrudescence and reinfections in treatment failure cases, and the genetic structure of the parasite population in the area were determined by nested family-specific PCR amplification of polymorphic regions of block 3 of $P$. falciparum antigen gene $m s p-2$ as described by Snounou et al [23] and Magesa et al [24]. The primers M2-OF and M2-OR, were used in the first round amplification. Two separate second round reactions were performed, one reaction using a pair of FC27 family-specific primers (M2-FCF and $M 2-F C R$ ) that detect the FC27-type variants, and the other reaction using a pair of 3D7/IC family-specific primers (M2-ICF and M2-ICR) that detect the 3D7/ICtype variants of MSP2.

Direct DNA sequencing of the pfcrt gene from three representative field samples was carried out by Lark Technologies. DNA was amplified using nested PCR using a number of primers that flank the 13 exons of the pfcrt gene (DJ Johnson personal communication).

\section{Ethical approval}

This study was approved by the Ethical Committees of the Ministry of Public Health, the Faculty of Medicine \& Health Sciences, Aden University in Yemen, and the Liverpool School of Tropical Medicine.

\section{Results}

In-vivo treatment outcomes

Of 644 febrile patients coming to the hospital, 225 (34.9\%) were positive for P. falciparum mono infection, of which $124(55.1 \%)$ were qualified for enrollment because they met all the inclusion criteria mentioned in the methods section. Patients of different age groups were enrolled (median 9.5, range 1-40). Of the122 cases that completed the follow-up, 48 (39.3\%) had adequate clinical and parasitological response (ACPR), the remaining $74(60.7 \%)$ were treatment failures. They were classified as Early Treatment Failures (ELF) 28 (23\%), Late Clinical Failures (LCF) 16 (13.1\%), and Late Parasitological Failures (LPF) 30 (24.6\%).

\section{Predictors of chloroquine treatment failure}

In this analysis, treatment outcomes were grouped into two groups; Adequate Clinical and Parasitological Response (ACPR) and Treatment Failure (TF). The TF group includes ETF+LCF+LPF. In univariate analysis, the following factors were found to be significantly associated with increased risk of CQ treatment failure: 
younger age ( $<10$ years), fever $\left(\geq 37.5^{\circ} \mathrm{C}\right)$ and higher parasite density ( $\geq 25000$ parasites/ul blood) at presentation (Table 1).

Multivariate analysis using backward selection logistic regression confirmed that age less than 10 years is an independent predictor of CQ treatment failure (OR 8.7 95\% CI 3.6-21.01), while the presence of fever and high parasite count lost their statistical significance. Body weight was dropped from multivariate analysis since it has a high correlation with age; Pearson correlation [25]= $0.890, p<.001$. Among the treatment failure group the presence of fever (axillary temperature $\geq 37.5^{\circ} \mathrm{C}$ ) at presentation, in addition to younger age ( $<$ five years) were found to be strong independent predictors of early treatment failure compared to late treatment failure $(\mathrm{OR}=$ 5.7 95\% CI 1.96-16.58 and OR $=3.42$ 95\% CI 1.04-11.21 for temperature and age respectively. Among late treatment failures, children less than 10 years of age were significantly at higher risk of being late clinical failures, compared to late parasitological failures, than older children and adults $\left(x^{2} p\right.$ value $\left.=.003\right)$.

\section{Analysis of pfcrt76 point mutation}

DNA was successfully amplified in all 112 pre-treatment samples. Of them, 109 (97.3\%) carried the pure mutant T76 allele, $1(0.9 \%)$ sample showed a mixed mutant and wild pfcrt genotypes, and $2(1.8 \%)$ contained the pure wild K76 allele. In post-treatment samples DNA amplification was successful in 71 samples, 66 of which (93\%) carried the pure mutant (T76) allele, 4 (5.6\%) had mixed pfcrt genotype, and 1 (1.4\%) carried the pure wild K76 allele. The pfcrt T76 was found in all post-treatment samples of patients who failed CQ treatment. Parasites carrying the wild K76 allele before treatment were not able to survive CQ treatment.
Analysis of $p f c r t 76$ polymorphisms in the pre-treatment samples of 68 cases showed that 67 samples (98.5\%) had the pure mutant T76 allele, one sample had mixed mutant and wild genotypes and none had the pure wild K76 allele. However, 42 of 44 (95.5\%) of ACPR cases for whom DNA was available for analysis also appeared to have the pure mutant T76 allele in their pre-treatment samples. There was, therefore, no association between the presence of either the mutant T76 or the wild K76 allele and the treatment outcome; Fisher exact $p$-value $=0.152$ (mixed genotype was added to the mutant). The prevalence of pre-treatment $p f c r t 76$ polymorphisms in different categories of treatment outcome is shown in Table 2.

Sequencing the $p f c r t$ gene of Yemeni parasites confirmed that Yemeni CQ resistant P. falciparum carry the old world (Asian and African) CQ resistant haplotype CVIETSESI at positions 72,73,74,75,76,220,271, 326 and 371.

\section{Effect of age on the association between pfrt76 mutation and outcome}

The base-line prevalence of $p f c r t$ T76 (and T76/K76) $110 / 112(98.2 \%)$ was higher than that of clinical chloroquine resistance $68 / 112(60.7 \%)$. To determine whether partial immunity developing with prolonged exposure to malaria contributed to the ability to clear infections caused by parasites carrying pfcrt T76, the proportion of infections by parasites carrying pfcrt T76 that cleared in children younger than 10 years of age were compared with the proportion of infections by parasites carrying pfcrt T76 that cleared in older children and adults. In the younger group, only 12.7 percent of 55 pre-treatment infections by parasites carrying the T76 mutation were successfully cleared by chloroquine, whereas in the older group 64.8 percent of 54 pre-treatment infections by

Table 1 Univariate analysis of some of the potential predictors of chloroquine treatment failure

\begin{tabular}{|c|c|c|c|c|}
\hline Variable (no.) & Number of treatment failure & Odds ratio & $95 \% \mathrm{Cl}$ & $p$-value \\
\hline \multicolumn{5}{|l|}{ Age (122) } \\
\hline$\geq 10$ years $(60)$ & 22 & 1.00 & - & \\
\hline$<10$ years $(62)$ & 52 & 8.98 & $3.54-23.33$ & 0.000 \\
\hline \multicolumn{5}{|l|}{ Age (122) } \\
\hline$\geq 15$ years $(24)$ & 4 & 1.00 & - & \\
\hline < 15 years $(98)$ & 70 & 12.5 & $3.65-53.56$ & 0.000 \\
\hline Sex & & 0.93 & $0.42-2.06$ & 0.839 \\
\hline \multicolumn{5}{|l|}{ Axillary temperature (122) } \\
\hline$<37.5^{\circ} \mathrm{C}(79)$ & 42 & 1.00 & - & \\
\hline$\geq 37.5^{\circ} \mathrm{C}(43)$ & 32 & 2.56 & $1.06-6.30$ & 0.022 \\
\hline \multicolumn{5}{|l|}{ Parasite count (122) } \\
\hline$<25000 /$ ul blood $(100)$ & 56 & 1.00 & - & \\
\hline$\geq 25000 /$ ul blood (22) & 18 & 3.54 & $1.02-13.39$ & 0.025 \\
\hline Body weight (Kg) & & .891 & $.853-.931$ & 0.000 \\
\hline
\end{tabular}


Table 2 Prevalence of pfcrt76 polymorphisms in pre-treatment samples in different categories of CQ treatment outcomes

\begin{tabular}{lccccc}
\hline & \multicolumn{3}{c}{ Treatment outcome } \\
\hline Type of pfcrt-76 polymorphism & ACPR (\%) & ETF (\%) & LCF (\%) & LPF (\%) & All (\%) \\
\hline Pfcrt-T76 mutant-type & $42(95.5)$ & $23(100)$ & $15(100)$ & $29(96.7)$ & $109(97.3)$ \\
\hline Pfcrt-K76 wild-type & $2(4.5)$ & 0 & 0 & 0 & $2(1.8)$ \\
\hline Pfcrt-T76/K76 mixed-type & 0 & 0 & 0 & $1(3.3)$ & $1(0.9)$ \\
\hline Total (\%) & $44(100)$ & $23(100)$ & $15(100)$ & $30(100)$ & $112(100)$ \\
\hline
\end{tabular}

parasites carrying T76 mutation were cleared by the drug, $X^{2}$ p-value $<0.0001$ (Figure 1).

Validation of the use of pfcrt -T76, as a molecular marker of in vivo chloroquine treatment failure

The sensitivity of the test, calculated by categorizing the treatment outcome into 2 categories; treatment failure (including $\mathrm{ETF}+\mathrm{LCF}+\mathrm{LPF}$ ) and treatment success represented by ACPR, was found to be $100 \%$, but the test was poorly specific (specificity $=4.5 \%, 95 \% \mathrm{CI}=0.0$ 10.7), The positive predictive value PPV was also low $(\mathrm{PPV}=61.8 \%, 95 \% \mathrm{CI}=52.7-70.9)$. This result was expected due to the finding of high base-line prevalence of $p f c r t \mathrm{~T} 76$ compared to clinical chloroquine treatment failure. Therefore, the genotype failure index GFI defined as the ratio of the prevalence of the resistant genotype (T76\%) to the prevalence of chloroquine therapeutic failure both early and late (ETF\%+LCF\%+LPF\%) was calculated and was found to be $1.6(97.3 / 60.7)$ for all ages. Controlled for age, the GFI was found to be 1.2 $(98.4 / 83.9)$ in children less than 10 years, whereas in older children and adults it increased to $2.8(98.3 / 36.7)$.

\section{Screening for the presence of PfcrtS163R}

The presence of mutation pfcrtS163R was studied in 30 randomly selected pre-treatment samples of 42

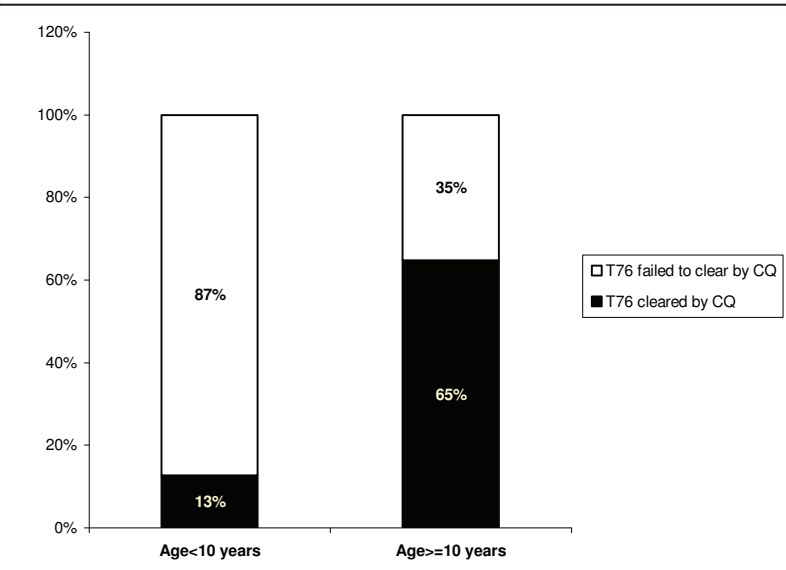

Figure 1 Effect of age on the in-vivo clearance of parasites carrying pfcrt-76 mutation. samples of patients who, despite the presence of $p f c r t \mathrm{~K} 76 \mathrm{~T}$ in their pre-treatment samples, did respond adequately to CQ (classified as ACPR with the in-vivo test). None of the 30 samples was found to carry the pfcrtS163R.

\section{Detection of dhfr-C59R and dhps-K540E}

Using the method developed by Plowe et al [17] amplification of DNA to detect $d h f r-C 59 \mathrm{R}$ was performed in 119 pre-treatment samples. Amplification was successful in $80.7 \%(96 / 119)$ of the samples. Attempts to repeat and optimize the PCR in the 23 samples that failed amplification were not successful. In order to increase the sensitivity of the detection of $d h f r$ polymorphism at codon 59, amplification was repeated in the failed 23 samples using an alternative PCR protocol developed by Duraisingh et al [22]. This resulted in successful amplification of only $13 \%(3 / 23)$ of the samples. Using the two PCR protocols for the detection of $d h f r-C 59 R$, amplification was successful in 83\% (99/119) of the samples. Of the 99 successfully amplified samples 4 (4\%) samples contained the dhfr-R59 mutant-type, one sample (1\%) had the mixed-type C/R59 and 94 samples (95\%) had the wild-type $d h f r-C 59$. The mutant to wild genotype prevalence ratio $(\mathrm{M} / \mathrm{W})$ was calculated and found to be 0.05 (5/96). Amplification of DNA to detect the dhps540 polymorphism was successful in all the 119 pretreatment samples tested. All samples (100\%) had the wild-type dhps-K540.

\section{Distinguishing recrudescence from reinfection using MSP 2}

Twenty-four paired samples (pre-treatment and posttreatment) of patients who failed CQ treatment between day 7 and day 14 (LCF and LPF) were successfully amplified and thus included in this analysis. Seventy-one percent $(17 / 24)$ of the samples had exactly the same alleles in both the primary sample and the recrudescent sample and they were classified as recrudescence. Twenty-one percent (5/24) of the samples had recrudescent plus new alleles in the recrudescent sample and were classified as indeterminate, and $8 \%(2 / 24)$ of the samples had only new alleles in the recrudescent sample and were classified as reinfection. 


\section{Discussion}

The present report gives the first account on anti-malarial molecular markers in Yemen, their frequency and their association with therapeutic response. Documentation of this baseline data is essential for surveillance of drug resistance and for global mapping of anti-malarial drug resistance. It is also the first report of the sequence of the pfcrt gene of Yemeni malaria parasites and the haplotype associated with CQR P. falciparum parasites from Yemen. Provision of such baseline information on the $p f c r t$ gene from different geographical areas is essential for an understanding of the evolution of CQR in parasite populations [12].

The in vivo test described in this study indicates a high proportion of chloroquine treatment failure (61\%). Subsequent therapeutic efficacy tests reported high levels of chloroquine resistance in other parts of Yemen and this lead to revision of the national malaria treatment policy, by switching the first-line treatment for uncomplicated falciparum malaria from $\mathrm{CQ}$ to the combination of $\mathrm{SP}+\mathrm{AS}$ in 2005 (unpublished data, Dr H. Atta].

Multivariate analysis confirmed that young age is a strong, independent predictor of CQ treatment failure in this study. This could be explained by age being a surrogate of immunity in malaria endemic areas. The age association with treatment outcomes has been reported in areas of stable transmission e.g., Uganda [26], Ghana [27], as well as in areas of unstable transmission. In areas of unstable malaria in Sudan, Abdel-Hameed et al [28] reported that drug resistant cases of falciparum malaria were predominantly children, leading the authors to suggest the inclusion of children as a subgroup when testing efficacy in low transmission settings as they have a higher risk of therapeutic failure. Adam et al [29] studied the factors that identify patients at risk of malaria treatment failure in an area of unstable malaria transmission in eastern Sudan. They analysed data from six clinical anti-malarial trials for uncomplicated falciparum malaria. They found that ability to clear CQ resistant parasites was significantly dependent on age, but not on the level of initial parasitaemia. Khalil et al [30] compared factors influencing parasite clearance after treatment in areas of different transmission intensity in Sudan and Tanzania. They found that parasite clearance was significantly associated with the initial level of parasitaemia (with P-values of 0.05 in Tanzania and 0.01 in Sudan) and with age (with P-values of 0.02 in Tanzania and 0.001 in Sudan). It seems that although previous observations indicated that the $76 \mathrm{~T}$ and $86 \mathrm{Y}$ alleles play a role in the mechanism of CQ resistance, there is evidence that other factors, such as the level of parasitaemia when treated and age, are also important. The $76 \mathrm{~T}$ and $86 \mathrm{Y}$ alleles could still be used as predictive markers for CQR, in non-immune individuals and low-transmission areas.
The wild-type K76 was detected in only $1.8 \%$ of pre-treatment sample.

Talisuna et al [31] found that the prevalence of infections carrying the K76 wild genotype was more closely related to CQ resistance than that of the T76 mutated genotype. They suggested that the disappearance of infections with the wild genotype may be one of the last stages of the long process resulting in CQ resistance, and that drug pressure must be an important factor in this process. Drug pressure would probably select the T76 mutation and would consequently decrease the prevalence of the wild type (K76) [32]. The widespread use of CQ in this population might have highly selected for CQ resistant mutants in the parasite population. Bin Dajem and AlQahtani [33] have recently found mutant T76 in all 95 samples tested in an endemic area in southwest Saudi Arabia bordering Yemen.

In the present study, the prevalence of T76 (98\%) was higher than the prevalence of in-vivo CQ treatment failure (61\%). It was found that the T76 was present in all pre-treatment, as well as, post-treatment samples of patients who failed CQ treatment, and the only two pretreatment samples that contained the wild K76 allele alone were belonging to patients who adequately responded to $C Q$, this indicates an absolute selection of the T76 mutation by the drug. The T76 genotype in pre treatment isolates was not predictive of in-vivo treatment failure. Similar finding of high prevalence of infection with theT76 genotype in pre-treatment isolates, which was not predictive of in-vivo failure level was observed in Sudan [34], Uganda [27], and in Loas [35]. These studies, like the present study, were conducted on patients seeking medical care, a selected group more likely to have taken anti-malarial drugs as compared to the general population $[36,37]$. Such results led to the conclusion that the presence of T76 may be necessary, but not sufficient, to predict in vivo treatment outcome in all patients. In vivo resistance may be influenced by a variety of factors, in addition to the K76T in $p f c r t$, including individual variations in drug absorption, pharmacokinetics, the underlying innate and acquired immune response, and the presence of additional mutations or compensatory changes in expression of other genes that may influence the level of resistance and ultimately the treatment outcome of patients infected with parasites that already display the K76T mutation. Giha et al [38] found evidence of clustering of treatment failure at level of individuals and households with differences in baseline immunity between the treatment failure prone individuals and treatment responders, suggesting an immune-mediated genetic susceptibility to treatment failure, as some of the tested polymorphisms showed trends but no significant association with treatment failures. 
The presence of PfcrtT76 in P. falciparum isolates in pre-treatment samples was poorly predictive of treatment outcome mainly because of the higher prevalence of the molecular marker for resistance, T76, than the in-vivo drug resistance due to the presence of T76 in pre-treatment samples of patients adequately responding to CQ. This finding has been noticed in nearly all studies [39]. This makes the application of this marker as a tool for surveillance challenging. Therefore, the ratios between the prevalence of the resistance genotype and the prevalence of the therapeutic failure (genotype-failure index GFI) were calculated [40]. The increase in the GFI with age in this study was consistent with Mali studies and reflects an acquired immunity and a higher proportion of older persons who cleared parasites with the CQ-resistant genotype when treated with CQ; it also reflects the intensity of transmission in the area. The role of immunity in clearance of resistant parasites was also observed in Burkina Faso, where children in ITC villages experienced an adequate clinical response more than children in non-ITC villages [41]. Induction of immunity through reduced exposure to malaria was explained by the frequent low density infection in children in ITC villages compared to frequent high density infections in children in non-ITC villages [41].

The finding of $5 \%$ of $d h f r$-R59 suggests that the prevalence of $d h f r$ Asn-108 and $d h f r$ Ile-51 mutations is higher than $5 \%$. Previous studies showed that the prevalence of dhfr- C59 has been found to be lower than that of the other two $d h f r$ mutations (dhfr Asn-108 and Ile-51) [42-44]. This might be explained by the idea of stepwise accumulation of $d h f r$ mutations that follows the order Asn-108 $\rightarrow$ Ile-51 $\rightarrow$ Arg-59. The absence of dhps-E540 is similar to the finding of Khalil et al [45] in Khartoum in Sudan and similar to that of the Middle East were parasites are generally of wild-type dhps [46]. The stepwise process in selection of SP resistance might also explain the absence of dhps-E540 in the studied samples. According to different studies, it was found that, in areas of a high level of immunity, triple mutant $d h f r$ with or without mutant dhps could be the main genetic determinant of SP treatment failure [43,47-49]. However, Alker et al [50] have found that dhps-437 and dhps-540 were strongly associated with SP treatment failure, while $d h f r-59$ was only weakly associated in eastern Democratic Republic of Congo.

Talisuna et al [51] suggested that $d h f r$ codon 59 mutant to wild genotype ratio $\mathrm{M} / \mathrm{W}$ is a simple and robust molecular marker that could be used for early detection of low SP treatment failure. In the present study, although not a population-based study, the M/W genotype ratio for the $d h f r$ codon 59 was calculated to provide base-line information and help in monitoring the emerging SP resistance in Yemen. The ratio was found to be $0.05(5 / 95)$ and according to Talisuna et al
[51] this might predict $<10 \%$ SP treatment failure. A therapeutic efficacy trial of SP monotherapy was conducted in the study area in 2004 and found treatment failure of $5 \%$ [unpublished data, Dr. H. Atta]. The result of this study of the SP molecular markers indicated generally that the prevalence of the triple mutation indicated by $d h$ fr Arg-59 was relatively low, 5\%, whereas the dhps Glu-540 was very rare suggesting that the selection process had not reached dhps. However, eight years have passed since the study, and in this area where the people are aware that CQ is no longer effective in treating malaria and where SP is readily available even over the counter in pharmacies further selection of $d h f r$ and dhps mutations might have rapidly taken place. Significant increase in the frequency of $d h f r-59$ and dhps -540 mutations was noticed in Sudan and Uganda over 3-4 year period $[52,53]$. This could compromise the efficacy of SP/AS combination, which is the current first-line treatment for falciparum malaria in Yemen. Preliminary results of therapeutic efficacy tests for the combination of SP+AS done in 2009-2010 indicate that it is still successful with the latest studies reporting $100 \%$ adequate clinical and parasitological response rates in two sites (Sharia-Almqarba in Odein), but showed a total failure rate of $2 \%$ in one site (Tor Bani Qais) [unpublished data, Dr H. Atta]. Close monitoring with molecular markers is needed to so that the identification of early markers of resistance will facilitate more widespread deployment of rational treatment policies that will retard the emergence of anti-malarial drug resistance.

\section{Acknowledgements}

Part of this study was supported by the joint EMRO/DCD/TDR Small Grants Scheme for Operational Research in Tropical and other Communicable Diseases and Essential Drugs and Biological programme of the World Health Organization. We would like to thank the WHO regional office, Yemen, the Ministry of Public Health, Yemen, the Roll Back Malaria Centre, and the Public Health and Population Office, Lahj Governorate for the appreciated efforts to facilitate the fieldwork. Many thanks for our patients for their help and cooperation

\section{Author details}

${ }^{1}$ Genetics and Immunology, Department of Physiological Sciences, Faculty of Medicine and Health Sciences, Aden University, Yemen. ${ }^{2}$ College of Medicine, King Saud University, Riyadh, Saudi Arabia. ' 'Liverpool School of Tropical Medicine, Pembroke Place, Liverpool L3 5QA, UK.

\section{Authors' contributions}

RAM: principal investigator, conducted the field work, molecular marker and sequencing tests, data analysis, wrote the manuscript. AAA: participated in establishment of the field work, data analysis, wrote the manuscript. MLC: Participated in establishment of the molecular and sequencing tests, data analysis, revised the manuscript. AAH: general supervision of the work, revising the manuscript. All authors read and approved the final manuscript.

\section{Competing interests}

The authors declare that they have no competing interests.

Received: 20 March 2011 Accepted: 21 August 2011

Published: 21 August 2011 


\section{References}

1. WHO: World Malaria report 2010 [http://www.who.int/malaria/publications/ country-profiles/profile_yem_en.pdf].

2. WHO: Chemotherapy of malaria and resistance to antimalarials Geneva, World Health Organization, 1973 (WHO Technical Report Series, No. 529).

3. Report on the Intercountry Workshop on Monitoring Therapeutic Efficacy of Antimalarial Drugs, Annex 5: Main results of monitoring drug resistance of falciparum malaria by country. Sana'a, Republic of Yemen WHO-EM/MAL/281/E/L; 2002, 21-25[http://whqlibdoc.who.int/emro/2002/ WHO-EM_MAL_281_E_L.pdf], accessed 24 February 2011.

4. Berga DK: Assignment report on monitoring therapeutic efficacy of chloroquine for treatment of uncomplicated falciparum malaria in republic of Yemen 21 December 1998 - 18 January 1999, Accessed 2March 2011: http:// www.emro.who.int/rbm/countryreports/yemen/YEM.doc.

5. WHO: Monitoring antimalarial drug resistance, Report of WHO Consultation, Geneva, Switzerland, 3-5 December 2001. WHO monographs WHO/CDS CSR/EPH/2002.7 and HO/CDS/RBM/2002.29.

6. Wellems T, Plowe C: Chloroquine-resistant malaria. J Infect Dis 2001, 184:770-776.

7. Wongsrichanalai C, Pickard AL, Wernsdorfer WH, Meshnick SR: Epidemiology of drug-resistant malaria. Lancet Infect Dis 2002, 2:209-218.

8. White NJ: Antimalarial drug resistance. J Clin Invest 2004, 113:1084-1092.

9. Hayton K, Su XZ: Genetic and biochemical aspects of drug resistance in malaria parasites. Curr Drug Targets Infect Disord 2004, 4:1-10.

10. Kublin JG, Cortese JF, Njunju EM, Mukadam RA, Wirima JJ, Kazembe PN, Djimdé AA, Kouriba B, Taylor TE, Plowe CV: Reemergence of chloroquinesensitive Plasmodium falciparum malaria after cessation of chloroquine use in Malawi. J Infect Dis 2003, 187:1870-1875.

11. Cooper RA, Ferdig MT, Su XZ, Ursos LM, Mu J, Fujioka H, Fidock DA, Roepe PD, Wellems TE: Alternative mutations at position 76 of the vacuolar transmembrane protein PfCRT are associated with chloroquine resistance and unique stereospecific quinine and quinidine responses in Plasmodium falciparum. Mol Pharmacol 2002, 61:35-42.

12. Cooper RA, Hartwig CL, Ferdig MT: Pfcrt is more than the Plasmodium falciparum chloroquine resistance gene: a functional and evolutionary perspective. Acta Trop 2005, 94:170-180.

13. Picot $S$, Olliaro $P$, de Monbrison F, Bienvenu AL, Price RN, Ringwald P: A systematic review and meta-analysis of evidence for correlation between molecular markers of parasite resistance and treatment outcome in falciparum malaria. Malar J 2009, 8:89.

14. Basco LK, Tahar R, Ringwald P: Molecular basis of in vivo resistance to sulfadoxine-pyrimethamine in African adult patients infected with Plasmodium falciparum malaria parasites. Antimicrob Agents Chemother 1998, 42:1811-1844.

15. Cowman AF, Morry MJ, Biggs BA, Cross GA, Foote SJ: Amino acid changes inked to pyrimethamine resistance in the dihydrofolate reductasethymidylate synthase gene of Plasmodium falciparum. Proc Natl Acad Sci USA 1988, 85:9109-9113.

16. de Pecoulas PE, Basco LK, Le Bras J, Mazabraud A: Association between antifol resistance in vitro and DHFR gene point mutation in Plasmodium falciparum isolates. Trans R Soc Trop Med Hyg 1996, 90:181-182.

17. Plowe CV, Djimde A, Bouare M, Doumbo O, Wellems TE: Pyrimethamine and proguanil resistance-conferring mutations in Plasmodium falciparum dihydrofolate reductase: polymerase chain reaction methods for surveillance in Africa. Am J Trop Med Hyg 1995, 52:565-568.

18. Kublin JG, Dzinjalamala FK, Kamwendo DD, Malkin EM, Cortese JF, Martino LM, Mukadam RA, Rogerson SJ, Lescano AG, Molyneux ME, Winstanley PA, Chimpeni P, Taylor TE, Plowe CV: Molecular markers for failure of sulfadoxinepyrimethamine and chlorproguanil-dapsone treatment of Plasmodium falciparum malaria. J Infect Dis 2002, 185:380-388

19. Plowe CV, Roper C, Barnwell JW, Happi CT, Joshi HH, Mbacham W, Meshnick SR, Mugittu K, Naidoo Inbarani, Price RN, Robert Shafer W, Sibley CH, Sutherland CJ, Zimmerman P, Rosenthal PJ: World Antimalarial Resistance Network (WARN). III: Molecular markers for drug resistant malaria. Malar J 2007, 6:121.

20. Djimde A, Doumbo OK, Cortese JF, Kayentao K, Doumbo S, Diourte Y, Dicko A, Su XZ, Nomura T, Fidock DA, Wellems TE, Plowe CV, Coulibaly D: A molecular marker for chloroquine-resistant falciparum malaria. N Engl J Med 2001, 344:257-263.
21. Johnson DJ: Studies on the molecular basis of chloroquine resistance inPlasmodium falciparum Ph.D. thesis 2003, University of Liverpool, UK

22. Duraisingh MT, Curtis J, Warhurst DC: Plasmodium falciparum: detection of polymorphisms in the dihydrofolate reductase and dihydropteroate synthetase genes by PCR and restriction digestion. Exp Parasitol 1998, 89:1-8.

23. Snounou G, Zhu X, Siripoon N, Jarra W, Thaithong S, Brown KN, Viriyakosol S: Biased distribution of msp1 and msp2 allelic variants in Plasmodium falciparum populations in Thailand. Trans $R$ Soc Trop Med Hyg 1999, 93:369-374.

24. Magesa SM, Mdira KY, Babiker HA, Alifrangis M, Farnert A, Simonsen PE, Bygbjerg IC, Walliker D, Jakobsen PH: Diversity of Plasmodium falciparum clones infecting children living in a holoendemic area in north-eastern Tanzania. Acta Trop 2002, 84:83-92.

25. Katz MH: Multivariate analysis. A practical guide for clinicians. Cambridge University Press; 1999.

26. Dorsey G, Kamya MR, Ndeezi G, Babirye JN, Phares CR, Olson JE, Katabira ET, Rosenthal PJ: Predictors of chloroquine treatment failure in children and adults with falciparum malaria in Kampala, Uganda. Am J Trop Med Hyg 2000, 62:686-692.

27. Ehrhardt S, Mockenhaupt FP, Agana-Nsiire P, Mathieu A, Anemana SD, Stark K, Otchwemah RN, Bienzle U: Efficacy of chloroquine in the treatment of uncomplicated, Plasmodium falciparum malaria in northern Ghana. Ann Trop Med Parasitol 2002, 96:239-247.

28. Abdel-Hameed AA, El-Jak IE, Faragalla IA: Sentinel posts for monitoring therapeutic efficacy of antimalarial drugs against Plasmodium falciparum in the Sudan. African Journal of Medicine and Medical Sciences 2001, 30(suppl):1-5.

29. Adam I, Elmardi KA, Malik EM: Predictors of antimalarial treatment failure in an area of unstable malaria transmission in eastern Sudan. Trans $R$ Soc Trop Med Hyg 2009, 103:21-4

30. Khalil IF, Alifrangis M, Tarimo DS, Staalsø T, Satti GM, Theander TG, Rønn AM, Bygbjerg IC: The roles of the pfcrt $76 \mathrm{~T}$ and pfmdr1 $86 \mathrm{Y}$ mutations, immunity and the initial level of parasitaemia, in predicting the outcome of chloroquine treatment in two areas with different transmission intensities. Ann Trop Med Parasitol 2005, 99:441-448.

31. Talisuna AO, Kyosiimire-Lugemwa J, Langi P, Mutabingwa TK, Watkins W, Van Marck E, Egwang T, D'Alessandro U: Role of the pfcrt codon 76 mutation as a molecular marker for population-based surveillance of chloroquine (CQ)-resistant Plasmodium falciparum malaria in Ugandan sentinel sites with high CQ resistance. Trans R Soc Trop Med Hyg 2002, 96:551-556.

32. Kyosiimire-Lugemwa J, Nalunkuma-Kazibwe AJ, Mujuzi G, Mulindwa H, Talisuna A, Egwang TG: The Lys-76-Thr mutation in PfCRT and chloroquine resistance in Plasmodium falciparum isolates from Uganda. Trans R Soc Trop Med Hyg 2002, 96:91-95.

33. Bin Dajem SM, Al-Qahtani A: Analysis of gene mutations involved in chloroquine resistance in Plasmodium falciparum parasites isolated from patients in the southwest of Saudi Arabia. Ann Saudi Medicine 2010, 30:187-192.

34. Babiker HA, Pringle SJ, Abdel-Muhsin A, Mackinnon M, Hunt P, Walliker D: High-level chloroquine resistance in Sudanese isolates of Plasmodium falciparum is associated with mutations in the chloroquine resistance transporter gene pfcrt and the multidrug resistance gene pfmdr1. Infect Dis 2001, 183:1535-1538.

35. Pillai DR, Labbe AC, Vanisaveth $V$, Hongvangthong B, Pomphida S, Inkathone S, Zhong K, Kain KC: Plasmodium falciparum malaria in Laos: chloroquine treatment outcome and predictive value of molecular markers. J Infect Dis 2001, 183:789-795.

36. Foster S: Treatment of malaria outside the formal health services. $J$ Trop Med Hyg 1995, 98:29-34.

37. McCombie SC: Treatment seeking for malaria: a review of recent research. Soc Sci Med 1996, 43:933-945.

38. Giha HA, ElGhazali G, Nasr A, Iriemenam NC, Berzins K, Troye-Blomberg M, Theander TG, Arnot D: Clustering of malaria treatment failure (TF) in Daraweesh: hints for host genetic susceptibility to TF with emphasis on immune-modulating SNPs. Infect Genet Evol 2010, 10:481-486.

39. Plowe $\mathrm{C}$ : Monitoring antimalarial drug resistance: making the most of the tools at hand. J Exp Biol 2003, 206:3745-3752. 
40. Djimde A, Doumbo OK, Steketee RW, Plowe CV: Application of a molecular marker for surveillance of chloroquine-resistant falciparum malaria. Lancet 2001, 358:890-891.

41. Diallo DA, Sutherland C, Nebie I, Ord R, Ilboudo-Sanogo E, Greenwood BM, Cousens SN: Children in Burkina Faso who are protected by insecticidetreated materials are able to clear drug resistant parasites better than unprotected children. J Infect Dis 2007, 196:138-44.

42. Sirawaraporn W, Sirawaraporn R, Cowman AF, Yuthavong Y, Santi DV: Heterologous expression of active thymidylate synthase-dihydrofolate reductase from Plasmodium falciparum. Biochemistry 1990, 29:10779-10785.

43. Peterson DS, Milhous WK, Wellems TE: Molecular basis of differential resistance to cycloguanil and pyrimethamine in Plasmodium falciparum malaria. Proc Natl Acad Sci USA 1990, 87:3018-22.

44. Plowe CV, Cortese JF, Djimde A, Nwanyanwu OC, Watkins WM, Winstanley PA, Estrada-Franco JG, Mollinedo RE, Avila JC, Cespedes JL, Carter D, Doumbo OK: Mutations in Plasmodium falciparum dihydrofolate reductase and dihydropteroate synthase and epidemiologic patterns of pyrimethamine- sulfadoxine use and resistance. J Infect Dis 1997, 176:1590-1596.

45. Khalil I, Alifrangis M, Ronn AM, Gabar HA, Jelinek T, Satti GM, Bygbjerg IC: Pyrimethamine/sulfadoxine combination in the treatment of uncomplicated falciparum malaria: relation between dihydropteroate synthase/dihydrofolate reductase genotypes, sulfadoxine plasma levels, and treatment outcome. Am J Trop Med Hyg 2002, 67:225-229.

46. Wang P, Lee CS, Bayoumi R, Djimde A, Doumbo O, Swedberg G, Dao LD, Mshinda H, Tanner M, Watkins WM, Sims PF, Hyde JE: Resistance to antifolates in Plasmodium falciparum monitored by sequence analysis of dihydropteroate synthetase and dihydrofolate reductase alleles in a large number of field samples of diverse origins. Mol Biochem Parasitol 1997, 89:161-177.

47. Omar SA, Adagu IS, Warhurst DC: Can pretreatment screening for dhps and dhfr point mutations in Plasmodium falciparum infections be used to predict sulfadoxine-pyrimethamine treatment failure? Trans $R$ Soc Trop Med Hyg 2001, 95:315-319.

48. Nzila AM, Mberu EK, Sulo J, Dayo H, Winstanley PA, Sibley CH, Watkins WM: Towards an understanding of the mechanism of pyrimethaminesulfadoxine resistance in Plasmodium falciparum: genotyping of dihydrofolate reductase and dihydropteroate synthase of Kenyan parasites. Antimicrob Agents Chemother 2000, 44:991-996.

49. Mutabingwa TK, Maxwell CA, Sia IG, Msuya FH, Mkongewa S, Vannithone S, Curtis J, Curtis CF: A trial of proguanil-dapsone in comparison with sulfadoxine-pyrimethamine for the clearance of Plasmodium falciparum infections in Tanzania. Trans R Soc Trop Med Hyg 2001, 95:433-438.

50. Alker AP, Kazadi WM, Kutelemeni AK, Bloland PB, Tshefu AK, Meshnick SR: dhfr and dhps genotype and sulphadoxine-pyrimethamine treatment failure in children with falciparum malaria in the Democratic Republic of Congo. Trop Med Int Health 2008, 13:1384-1391.

51. Talisuna AO, Langi P, Mutabingwa TK, Watkins W, Van Marck E, Egwang TG, D'Alessandro U: Population-based validation of dihydrofolate reductase gene mutations for the prediction of sulfadoxine-pyrimethamine resistance in Uganda. Trans R Soc Trop Med Hyg 2003, 97:338-342.

52. Menegon M, Talha AA, Carlo Severini, Elbushra SM, Mohamedani AA, Malik EM, Mohamed TA, Wernsdorfer WH, Majori G, Nour BYM: Frequency distribution of antimalarial drug resistance alleles among Plasmodium falciparum isolates from Gezira State, central Sudan, and Gedarif State, eastern Sudan. Am J Trop Med Hyg 2010, 83:250-257.

53. Dorsey G, Dokomajilar C, Kiggundu M, Staedke SG, Kamya MR, Rosenthal PJ: Principal role of dihydropteroate synthase mutations in mediating resistance to sulfadoxine-pyrimethamine in single-drug and combination therapy of uncomplicated malaria in Uganda. Am J Trop Med Hyg 2004, 71:758-763.

doi:10.1186/1475-2875-10-245

Cite this article as: Mubjer et al: Molecular markers of anti-malarial drug resistance in Lahj Governorate, Yemen: baseline data and implications. Malaria Journal 2011 10:245.

\section{Submit your next manuscript to BioMed Central and take full advantage of:}

- Convenient online submission

- Thorough peer review

- No space constraints or color figure charges

- Immediate publication on acceptance

- Inclusion in PubMed, CAS, Scopus and Google Scholar

- Research which is freely available for redistribution

Submit your manuscript at www.biomedcentral.com/submit 